\title{
Prevalence of psychiatric morbidity among inmates in Jos maximum security prison
}

\author{
Aishatu Y. Armiya' ${ }^{1 *}$, Ayodele Obembe ${ }^{1}$, Moses D. Audu ${ }^{1}$, Tolulope O. Afolaranmi ${ }^{2}$ \\ ${ }^{1}$ Department of Psychiatry, Jos University Teaching Hospital, Jos, Nigeria \\ ${ }^{2}$ Department of Community Medicine, Jos University Teaching Hospital, Jos, Nigeria \\ Email: *azuminiarmiyau@yahoo.com
}

Received 11 November 2012; revised 13 December 2012; accepted 22 December 2012

\begin{abstract}
Background: The prevalence of psychiatric illness in correctional settings is significantly elevated, with higher than community rates reported in most mental disorders. The prison is a correctional institution in which inmates have limited liberty, autonomy, and communication with family and friends. This can be devastating to some inmates thereby leading to deterioration in their physical, psychological and social wellbeing. The study was aimed to determine the prevalence of axis 1 psychiatric disorders and associated factors among prison inmates in Jos, Nigeria. Method: This was a cross-sectional descriptive study carried out in Jos maximum security prison among 608 inmates. Two sets of data collection instruments were used namely (General Health Questionnaire) GHQ-28 and (Composite International Diagnostic Interview) CIDI. SPSS statistical software package for windows version $\mathbf{1 5 . 0}$ was used for data analysis and test of significance was set at $P<0.05$. Results: Prevalence of psychiatric disorders was 347 (57\%), substance use disorder was the commonest disorder found in 169 (48.7\%). Psychiatric morbidity was significantly associated with age $(P=0.034)$ and prison status $(P=0.01)$. Conclusion: This study showed that there was a high rate of psychiatric disorders among prison inmates in Nigeria, which should be a concern to health care policy makers in the country. Recommendation: The establishment of functional psychiatric services with adequate manpower in prison will assist in the detection, treatment and correction of inmates.
\end{abstract}

Keywords: Prevalence; Morbidity; Prison; Psychiatric; Maximum Security

\section{INTRODUCTION}

Psychiatric morbidity generally refers to the incidence of

${ }^{*}$ Corresponding author. both physical and psychological deterioration as a result of a mental or psychological condition [1]. The term usually applies to those who are acutely aware of their condition, despite the mental deterioration. According to World Health Organisation, morbidity itself is measured according to the number of people affected, the types of illnesses, and how long the illness lasts [1].

The term mental disorder incorporates psychotic illness, neurotic disorders, substance misuse and personality disorder and related behaviour, notably (in prison context) self harm behaviour. Different studies have used different methods to estimate the prevalence of these conditions and so their estimates vary. However, all consistently demonstrate prevalence rates significantly higher within than outside the prison [2-6].

It has been known that psychiatric disorders are highly prevalent among prisoners [7]. Many people with identifiable psychiatric illness do conflict with the law, often by no fault of their own but because of symptoms of their psychiatric illness and end up in jails. Such symptoms include impaired judgement, lack of impulse control, suspiciousness, disinhibition, paranoia, inability to trust others, delusions and hallucinations. Although prisoners represent a very small proportion of the total population, approximately $0.1 \%$, they are likely to be extensive consumers of a wide range of health services [8]. A study in England estimated that $33 \%$ of prisoners in English prison were psychiatric cases [9]. The rate of psychopathology, observed was higher than the $20 \%$ conspicuous psychiatric morbidity in sub-urban general population assessed by a general practioner [10]. They suggested that the privations of imprisonment increased the risk of psychiatric morbidity. Dilapidated physical structures as often seen in prisons may imperil the health and safety of inmates.

A penal system is an official mechanism designed to maintain law and order in the society. Part of this mechanism is the prison, which is a special place where people who run afoul of the law are confined over a period of time [11]. It is meant to serve as a correctional 
instrument in rehabilitating offenders back to the society. This can be devastating to some inmates thereby leading to deterioration in their physical, psychological and social wellbeing.

In Nigeria there are alternative ways of dealing with offences. These included fines, isolation from social contact, exile and community work, depending on the gravity of the offences committed apart from prison sentences. In Nigeria, studies on the prevalence of psychiatric morbidity among prison inmates are few and most of them carried out in the southern part of the country. Due to the paucity of data on studies of psychiatric morbidity in Nigeria, with the burden and extent of psychiatric disorders among prisoners this study was conducted to provide insight into the need to screen incoming inmates in order to detect psychiatric disorders amongst them.

The aim of this study was to identify the prevalence of psychiatric morbidity among inmates in the prison and also to provide relevant information on psychiatric morbidity among inmates in the northern part of the country. It is hoped that this will contribute significantly to future planning and initiatives concerning the care and treatment of mentally ill inmates. Furthermore, the data obtained from this study will provide a vital platform for further analysis regarding the particular difficulties being experienced by various populations of inmates.

\section{METHODOLOGY}

\subsection{Study Design and Location}

This was a cross-sectional, descriptive study conducted in two stages among 608 male inmates in Jos maximum prison, Plateau State.

\subsection{Data Collection}

In the first stage, every inmate was given a questionnaire booklet consisting of socio-demographic and General Health Questionnaire 28 (GHQ-28), an instrument that has been validated among prison population and used in this environment [12-15]. The second stage involved interview with Composite International Diagnostic Interview (CIDI) for assessing psychiatric morbidity, an instrument which has been validated, and used by researchers in different countries including Nigeria $[16,17]$.

\subsection{Sociodemographic and Forensic Questionnaires}

The Sociodemographic and Forensic questionnaires were designed by the authors to enquire about basic epidemiological variables including age, sex, occupation, marital status and religion and forensic variables such as prison status, duration of stay in prison and type of offence committed.

\subsection{General Health Questionnaire (GHQ-28)}

This is a self administered screening instrument which was given to all participating inmates. It was designed to cover four identifiable areas of distress: depression, anxiety, social impairment and hypochondriasis. Although it was not intended to detect severe illness such as schizophrenia or psychotic depression however, repeated experiences with the GHQ scale has shown that it can be used to screen for the presence of these disorders in people (Goldberg D) [10]. It is used as a screening instrument for mental disorders following which the diagnosis is confirmed with a more specific instrument. The originnal version contains 60 item questions, which was designed by Goldberg in 1972, but shorter versions such thirty (30), twenty eight (28), and twelve (12) were developed later. However, the GHQ-28 was used for this study. It consists of four sub scales measuring somatic symptoms, anxiety and insomnia, social dysfunction, and severe depression. Items on the GHQ may be scored using 0-1-2-3 Likert scale or 2 point score rate in which the problems are either present or absent. The GHQ questionnaires have been used in over 38 countries including Nigeria and over 50 validity studies have been published. It has been demonstrated to have high sensitivity and specificity [14]. In most Nigerian studies the cut off has been determined at four (4), a level at which the instrument has optimal sensitivity and specificity while a score of (3) or below signifies absence of psychopathology [8].

\subsection{The Composite International Diagnostic Interview (CIDI)}

This was administered to all those with GHQ score of four and above. CIDI is a comprehensive, fully standardized interview that can be used to assess mental disorder and provide diagnosis according to the definition and criteria of the tenth revision of the International Classification of Diseases ICD-10 (WHO 1992, 1993) and the fourth edition of the Diagnostic and Statistical Manual of mental disorder (DSM IV) (American Psychiatric Association). The CIDI was designed for use in variety of cultures $[18,19]$. The format of the interview will be to elicit life time of 12 month period of the presence of a symptom and using a number of probes to establish whether the symptom is of psychiatric importance.

\subsection{Analysis}

Data was statistically analysed using the Statistical Package for Social Sciences (SPSS) for windows version 15.0. The frequency distributions of these variables, mean and standard deviation were calculated, and a probability of $5 \%$ was regarded as statistically significant. 


\section{RESULTS}

In this study about half (49.0\%) of the subjects were within the age group 25 - 34 years (Table 1). More than half of the subjects were single (53\%), with $392(64.5 \%)$ practising Christianity. Two hundred and seventy seven (45.5\%) were unemployed before incarceration, while $152(25 \%)$ who were employed before incarceration using the International Labour Organisation (UNO/ILO) classification of occupation ( $42 \%$ ) were peasant farmers (Major group 4) (Table 1).

Three hundred and sixty-five $(60 \%)$ of the subjects were awaiting trial and the rest had received various jail terms. For the convicted subjects, majority $60 \%$ have spent between 0 - 24 months before conviction (Table 1). Half of the convicted subjects were sentenced to death 124 (51.0\%), various prison sentences accounted for 108 (44.4\%), while $11(4.6 \%)$ got life imprisonment. Duration of stay in prison before conviction in months was between 0 - 305 months with mean months of $42.9 \pm$ 65.6 (Table 1). Seventy five (12.3\%) of the studied subjects had previous prison detention of which $66(83.5 \%)$ were detained between 1 - 4 times while $3(4 \%)$ were in prison between 9 - 12 times.

The prevalence of psychiatric disorders among prison inmates in this study was $57 \%$ while Substance use disorder was the commonest psychiatric diagnosis occurring in $48.7 \%$ of the subjects closely followed by Depression in $30.8 \%$ of the subjects (Table 2).

Age was significantly associated with psychiatric disorders, $92.3 \%$ of the subjects with psychiatric disorder were aged 65 year and above with the trend also seen with increasing age $(\mathrm{P}=0.034)$. prison status was also found to have statistically significant relationship with psychiatric morbidity as more than half of both convicted and awaiting trial subjects had psychiatric morbidity when compared with those without psychiatric morbidity $(\mathrm{P}=0.01)$.

\section{DISCUSSION}

Majority of the subjects studied were young males, single, with low educational achievement. The age bracket 25 - 34 years constituted nearly half of those studied. This is similar to findings from studies conducted in Western Nigeria and United States of America where preponderance of single young adults was found among the studied subjects $[8,20]$. Similar findings were also observed in studies carried out in Northern and Southern Nigeria where $50 \%$ and $62.8 \%$ of the subjects were young adults $[21,22]$. These findings suggests that younger people tend to be more aggressive due to multiplicity of factors that interact with each other such as lots of energy, unemployment, isolation, generation gap (generation conflict), poor supervision, adventure and
Table 1. Sociodemographic and forensic characteristics of studied subjects.

\begin{tabular}{|c|c|c|c|}
\hline \multicolumn{4}{|c|}{$\mathrm{N}=608$} \\
\hline Varibles & Frequency & Percentage & Mean + SD \\
\hline \multicolumn{4}{|l|}{ Age group (years) } \\
\hline $15-24$ & 133 & 21.9 & \\
\hline $25-34$ & 298 & 49.0 & \\
\hline $35-44$ & 109 & 17.9 & $32.1 \pm 10.6$ \\
\hline $45-54$ & 35 & 5.8 & \\
\hline $55-64$ & 20 & 3.3 & \\
\hline$>65$ & 13 & 2.1 & \\
\hline \multicolumn{4}{|l|}{ Religion } \\
\hline Christianity & 392 & 64.5 & \\
\hline Islam & 209 & 34.3 & \\
\hline Traditional & 7 & 2.1 & \\
\hline \multicolumn{4}{|l|}{ Nationality } \\
\hline Nigerian & 600 & 98.7 & \\
\hline Others & 8 & 1.3 & \\
\hline \multicolumn{4}{|l|}{ Marital status } \\
\hline Married & 210 & 34.5 & \\
\hline Separated & 47 & 7.7 & \\
\hline Widowed & 7 & 1.2 & \\
\hline Divorced & 19 & 3.1 & \\
\hline Single & 325 & 53.5 & \\
\hline \multicolumn{4}{|l|}{ Educational status } \\
\hline No formal education & 108 & 17.8 & \\
\hline primary & 134 & 22.0 & \\
\hline Secondary & 286 & 47.0 & \\
\hline Tertiary & 80 & 13.2 & \\
\hline \multicolumn{4}{|l|}{ Employment status } \\
\hline Unemployed & 277 & 45.5 & \\
\hline Employed & 152 & 25.0 & \\
\hline Students & 104 & 17.1 & \\
\hline Others & 75 & 12.4 & \\
\hline \multicolumn{4}{|l|}{$\begin{array}{l}\text { Prison sentence } \\
\text { category }\end{array}$} \\
\hline Awaiting trials & 365 & 60.0 & \\
\hline Convicted & 243 & 40.0 & \\
\hline \multicolumn{4}{|l|}{$\begin{array}{l}\text { Duration of stay in } \\
\text { prison (months) }\end{array}$} \\
\hline$\leq 60$ & 457 & 75.2 & \\
\hline $61-180$ & 123 & 20.2 & $42.9+65.6$ \\
\hline $181-360$ & 28 & 4.6 & \\
\hline \multicolumn{4}{|l|}{ Offence charged } \\
\hline Murder & 106 & 17.4 & \\
\hline Manslaughter & 33 & 5.4 & \\
\hline Armed robbery & 229 & 37.3 & \\
\hline Others & 240 & 39.5 & \\
\hline
\end{tabular}


Table 2. Psychiatric morbidity of the studied subjects.

\begin{tabular}{ccc}
\hline & $\mathrm{N}=347$ & \\
\hline Type & Frequency & Percentage \\
\hline $\begin{array}{c}\text { Depression (D) } \\
\text { Generalised Anxiety } \\
\text { Disorder (G) }\end{array}$ & 107 & 30.8 \\
Panic Disorder (P) & 41 & 11.8 \\
Psychosis (PS) & 21 & 6.1 \\
$\begin{array}{c}\text { Substance Use } \\
\text { Disorder (SUD) } \\
\text { Mania (M) }\end{array}$ & 169 & 1.2 \\
$\begin{array}{c}\text { Intermittent Explosive } \\
\text { Disorder (IED) } \\
\text { Depression/ Substance } \\
\text { use disorder }\end{array}$ & 2 & 48.7 \\
\hline
\end{tabular}

peer pressure.

Most of the subjects were Christians (64.5\%). Though the prison is a maximum security prison with inmates from different parts of the country, most of the subjects were from the immediate environment which has a predominant Christian population.

One hundred and forty-five $(23.8 \%)$ of the subjects had completed secondary school education, subjects with no formal education and secondary school drop outs accounted for $17.8 \%$ respectively, while only $15(2.5 \%)$ had tertiary education. This concurs with the findings of some studies in Nigeria which showed similar pattern of educational status $[23,24]$. Good education or vocational training can provide an enhanced likelihood of legitimate source of income or influence a sense of reason to be a good citizen in a society; it may also equip the individual with the social skills needed to leave with people.

About half of the inmates (45.6\%) were unemployed as at the time of offence while only $25 \%$ were employed before incarceration. Of the total number of studied subjects with employment $26.3 \%$ were peasant farmers who are in Group 4 of the International Labour Organisation of Occupation (UNO/ILO). This is in agreement with the findings of studies conducted in Nigeria and Kenya $[8,25]$.

Duration of imprisonment in this study ranged from few days to 960 months with a mean of $42.9 \pm 65.6$ months. Most subjects (75.2\%) had spent few days to 60 months in prison. This finding is in synergy with the findings of some Nigerian studies [8,22,23]. However a study conducted in United States found that $60.1 \%$ of the subjects had spent less than 24 months in prison detention [20]. This has brought to light that probably inmates in Nigeria had longer incarceration period due to delay and complexity in the judiciary system.

The commonest crimes observed to be committed among the subjects in this study were violent crimes like armed robbery $(37.7 \%)$ and murder (16.4\%). Where theft $(21.1 \%)$, assault $(7.1 \%)$ and manslaughter $(2.3 \%)$ were the other crimes committed. The higher proportion of violent crimes could be explained by the fact that the study was conducted in a maximum security prison as against ordinary prison where cases of non violent offenders may be higher. These findings are in consonance with a hospital based study conducted among subjects in Nigeria where high rates of murder were found as the commonest violent offence committed [26]. However; findings from other studies conducted in Nigeria differed from this study $[8,21,24]$.

In this study more than half of the subjects $(57 \%)$ had a psychiatric morbidity. The finding is in conformity with findings of a study in Nigeria where majority $(83.7 \%)$ of the studied subjects had definite diagnosis of psychiatric disorders on CIDI. Studies from Australia, Iran and other parts of the world also found psychiatric morbidity in $80 \%, 57 \%, 55.4 \%, 51.4 \%$ and $43 \%$ of the studied subjects respectively using standardised instruments [8,26-30].

In this study substance use disorder, depression and generalised anxiety disorder were found in $48.7 \%, 30.8 \%$ and $11.8 \%$ among the subjects respectively. A study conducted in South Africa reported findings in support of this study as substance use disorder and depression with anxiety disorder were found in $42.0 \%$ and $23.3 \%$ of the subjects respectively [28]. Other studies carried out in Nigeria and France reported lower proportions of subjects with substance use disorder, depression and anxiety $[8,31]$.

Age was found to have statistical significance with psychiatric disorder as the rate of psychiatric disorder increases with increasing age. This is not in conformity with a similar Nigerian study where age was not found to be statistically significant with psychiatric morbidity [20]. The forensic variable found to be statistically significant was the prison status of the subject, as significantly more number of those with psychiatric disorders were convicts $(63.3 \%)$ than awaiting trial $(52.9 \%)$. This is in concordance to the findings in a Nigerian study where awaiting trial status was significantly associated with GHQ-30 caseness [32].

\subsection{Limitation}

The Composite International Diagnostic Interview (CIDI) used for diagnosis of psychiatric disorder in this study does not have provision for making diagnosis of personality disorder which would have embellished the study.

\subsection{Conclusion/Recommendation}

A high prevalence of psychiatric morbidity (57\%) was 
found in the prison pointing to the fact that urgent attention is required with the aim of reducing the burden of psychiatric disorders and addressing the possible stressors. The prison psychiatric unit needs to be upgraded to make it more service friendly. The possibility of providing facilities for long term care outside the prison set up should be considered in addition to formulation of policies favourable to the mentally ill offenders.

\section{ACKNOWLEDGEMENTS}

We acknowledge the Deputy Comptroller of prison services in Jos for the permission granted to us to carry out the study, the staff of the prison medical services, other warders and inmates whose cooperation and understanding made the study possible.

\section{REFERENCES}

[1] WiseGEEK, What is psychiatric morbidity? http://www.wisegeek.com/what-is-psychiatric\%20morbid ity

[2] Gunn, J., Maden, A. and Swinton, M. (1991) Treatment needs of prisoners with psychiatric disorder. British Medical Journal, 303, 338-341. doi:10.1136/bmj.303.6798.338

[3] Fazel, S. and Danesh, J. (2002) Serious mental disorder in 23,000 prisoners: A systematic review of 62 surveys. The Lancet, 359, 545-550. doi:10.1016/S0140-6736(02)07740-1

[4] Lader, A., Singleton, N. and Meltzer, H. (2000) Psychiatric morbidity among young offenders in England and Wales. Office of National Statistics, London.

[5] Singleton, N., Meltzer, H., Gatward, R., Coid, J. and Deasy, D. (1998) Psychiatric morbidity of prisoners in England and Wales. Office of National Statistics, London.

[6] Reed, J. (2002) Delivering psychiatric care to prisoners' problems and solution. Advances in Psychiatric Treatment, 8, 117-127. doi:10.1192/apt.8.2.117

[7] Coid, J. (1984) How many psychiatric patients in prison? British Journal of Psychiatry, 145, 78-86. doi:10.1192/bjp.145.1.78

[8] Agbahowe, S.A., Ohaeri, J.U., Ogunlesi, A.O. and Osahon, R. (1998) Prevalence of psychiatric morbidity among convicted inmates in a Nigerian prison community. East African Medical Journal, 75, 19-26.

[9] Gunn, J., Robertson, G., Dell, S. and Way, C. (1978) Psychiatric aspect of imprisonment. London Academic Press (citied by Gunn et al. 1991).

[10] Goldberg, D.P. and Blackwell, B. (1970) Psychiatric illness in a suburban general practise: A detailed study using a new method of case identification. British Medical Journal, 2, 439-443. doi:10.1136/bmj.2.5707.439

[11] Holmes, T.H. and Rahe, R.H. (1967) The social adjustment rating scale. Journal of Psychosomatic Research, 11, 213-218. doi:10.1016/0022-3999(67)90010-4
[12] Goldberg, D.P. (1970) The detection of psychiatric illness by questionnaire. A monograph (21). Oxford University Press, London.

[13] Black, D.W., Arndt, S., Hale, N. and Rogerson, R. (2004) Use of the Mini International Neuropsychiatry Interview (MINI) as a screening tool in prisons: Results of a preliminary study. Journal of American Academy of Psychiatry and Law, 32, 158-162.

[14] Gureje, O. and Obikoya, B. (1990) The GHQ-12 as a screening tool in a primary care setting. Social Psychiatry and Psychiatric Epidemiology, 25, 276-280. doi:10.1007/BF00788650

[15] Amoran, O., Lawoyin, T. and Lasebikan, V. (2007) Prevalence of depression among adults in Oyo State, Nigeria: A comparative study of rural and urban communities. Australian Journal of Rural Health, 15, 211-215. doi:10.1111/j.1440-1584.2006.00794.x

[16] Gureje, O. (1990) Psychiatric morbidity in an urban medical setting. A profile of unmet needs. An unpublished fellowship thesis submitted to the National Postgraduate Medical College of Nigeria.

[17] Gureje, O., Lasebikan, V.O., Lola, K. and Makanjuola, V.A. (2006) Life time and 12 months prevalence of mental disorder in the Nigerian survey of mental health and wellbeing. British Journal of Psychiatry, 188, 465-471. doi:10.1192/bjp.188.5.465

[18] World Health Organisation (1992,1993) ICD-10 classification of mental and behavioural disorders. Geneva.

[19] American Psychiatric Association (1994) The fourth edition of the Diagnostic and Statistical Manual of mental disorder (DSM-IV).

[20] Baillargeon, J. (2009) Psychiatric disorder and repeated incarceration: The revolving prison door. American Journal of Psychiatry, 166, 103-109. doi:10.1176/appi.ajp.2008.08030416

[21] Rabbebe, I.B. (1999) Prevalence of psychiatric morbidity among convicted inmates in Maiduguri prison. An unpublished fellowship thesis submitted to the West Africa College of Physicians.

[22] Agboola, A.A. (2006) A study of psychiatric and co-morbid physical illness among inmates in Calabar prison. An unpublished fellowship thesis submitted to the West Africa College of Physicians.

[23] Adesanya, A., Ohaeri, J.U. and Ogunlesi, O.A. (1993) Psychoactive substance abuse among inmates of a Nigerian prison population. Drug and Alcohol Dependence, 47, 39-44. doi:10.1016/S0376-8716(97)00067-7

[24] Kanyanya, I.M., Othieno, C.J. and Ndetei, D.M. (2007) Prevalence of psychiatric morbidity among convicted sex offenders at Kamiti prison Kenya. East African Medical Journal, 84, 151-155.

[25] Ogunlesi, O.A., Makanjuola, J.D.A. and Adelekan, M. (1988) Offenders admitted to neuropsychiatry hospital Aro-Abeokuta: A ten-year review. West African Journal of Medicine, 7, 3-4.

[26] Butler, T., Gavin, A., Stephen, A., Chika, S., Nadine, E.S. and John, B. (2006) Mental disorder in Australian prison. A comparison with a community sample. Australian/New 
Zealand Journal of Psychiatry, 40, 272-276. doi:10.1080/j.1440-1614.2006.01785.x

[27] Assadi, S.M. and Mahdi, P. (2006) Psychiatric morbidity among sentenced prisoners. A prevalence study in Iran. British Journal of Psychiatry, 188, 159-164. doi:10.1192/bjp.188.2.159

[28] Naidoo, S. and Mkize, D.L. (2012) Prevalence of mental disorders in a prison population in Durban, South Africa. African Journal of Psychiatry, 15, 30-35.

[29] Kugu, N., Akyuz, G. and Dogan, O. (2007) Psychiatric morbidity in murder and attempted murder crime convicts: A Turkey study. Forensic Science International, 175, 107-112. doi:10.1016/j.forsciint.2007.05.016
[30] Mafullul, Y.M. (1997) A psychosocial study of convicted homicide offenders in a Northern Nigerian prison. An unpublished fellowship thesis submitted to the West Africa College of Physicians.

[31] Falissard, B., Loze, J.Y., Gasquet, I., Duburc, A., de Beaurepaire, C., Fagnani, F. and Rouillon, F. (2006) Prevalence of mental disorder in French prison for men. BioMed Central Journal, 6, 33.

[32] Fatoye, F.O., Fatoye, G.K., Oyebanji, A.O. and Ogunro, A.S. (2006) Psychological characteristics as correlates of emotional burden in incarcerated offenders in Nigeria. East African Medical Journal, 83, 545-552. 